\title{
Initiation of gas-hydrate pockmark in deep-water Nigeria: Geo-mechanical analysis and modelling
}

\author{
Riboulot Vincent ${ }^{1,{ }^{*}}$, Sultan Nabil ${ }^{1}$, Imbert P. ${ }^{2}$, Ker Stephan ${ }^{1}$ \\ ${ }^{1}$ IFREMER, Centre de Brest, Institut CARNOT-EDROME, Brest, France \\ ${ }^{2}$ TOTAL, Pau, France \\ * Corresponding author : Vincent Riboulot, Tel.: +33 (0)298 224248; fax: +33 (0)298 224570. ; \\ email address : riboulot@ifremer.fr
}

\begin{abstract}
:
A review of recent literature shows that two geomorphologically different types of pockmarks, contribute to gas seepage at the seafloor. Type-1 pockmarks are defined as seafloor craters associated to fluid seepage and are the most classical type referred to as "pockmarks" in the literature. In contrast, Type-2 pockmarks reveal a complex seafloor morphology that may result from the formation/decomposition of gas hydrates in underlying sedimentary layers.

Interpretation of very-high-resolution seismic data, sedimentological analyses and geotechnical measurements acquired from the Eastern Niger Submarine Delta reveal that Type-2 pockmarks are associated to the presence at depth of a conical body of massive gas hydrates. Based on acquired data, theoretical analysis and numerical modelling, it was possible to propose a novel geo-mechanical mechanism controlling the irregular seafloor deformations associated to Type-2 pockmark and to show that pockmark shapes and sizes are directly linked to the initial growth and distribution of sub-seafloor gas hydrates. The study illustrates the role of gas hydrates formation in the fracturation, deformation of the subsurface sediment and the formation of Type-2 pockmarks.
\end{abstract}

\section{Highlights}

- The morphology of the pockmarks directly associated to the dynamic of gas hydrates. Initial stage of pockmark development is linked to the conical fracture formation. Mechanism of gas-hydratepockmark formation is determined with numerical calculations. Numerical calculations demonstrate the role of gas hydrates on subsurface fracturation. A novel geo-mechanical mechanism is proposed for the gas-hydrate-pockmark formation 
Keywords : pockmarks, gas hydrates, VHR seismic data, piezocone, numerical modelling, Niger Delta

\section{Introduction}

Pockmark formation, associated with gas (free or dissolved) and gas hydrates, often found in continental slope environments represent an overlooked mechanism possibly responsible for the transfer of large 
quantities of gas from seafloor sediments into the ocean and ultimately into the atmosphere, potentially contributing to atmospheric warming (e.g. Chand et al., 2012; Leifer and Judd, 2002; Solomon et al., 2009). The identification of pockmarks is therefore an important aim for industries to choice the location of the deep-water infrastructures. The sedimentary deformations linked to gas hydrates are poorly known but their localization are crucial because the modifications of pressure/temperature conditions near from gas hydrates could provoke sedimentary instabilities that may generate tsunamis.

Since the first study about pockmarks (King and MacLean, 1970), where they were considered as randomly distributed craters at the seafloor, many efforts have been made to understand the evolution of these structures. It is now widely accepted that pockmarks represent the morphological signature of fluid seepage through the seafloor (2.a; e.g. Hovland et al., 1984; 2005; Judd and Hovland, 2007), and can form organized arrays when the fluid they expel comes from underlying organized structures (e.g. Eichhubl et al., 2000; Forwick et al., 2009; Pilcher and Argent, 2007). Recent studies have evidenced sub-surface three-dimensional irregular depression morphologically different from classical pockmarks but resulting from fluid seepage linked to dissociation/dissolution of gas hydrates bearing underlying sedimentary layers (Figure 1.b ; Davy et al., 2010; Sultan et al., 2010; 2014).

Davy et al. (2010) and Sultan et al. (2010) have named the sub-surface sedimentary deformations related to gas hydrates, gas escape features and pockmarks, respectively. Macelloni et al. (2012) and Simonetti et al. (2013) have observed similar features in the Gulf of Mexico and the seafloor depressions over gas hydrates have been mentioned as craters. Riboulot et al. (2011) consider these features as pockmarks and have made a classification to make a distinction between two different features: (1) the conical depressions, commonly described in literature, are named Type-1 pockmarks and (2) the hydratebearing depressions are classified as Type-2 pockmarks (Figure 1). Sultan et al., (2010) propose a detailed model controlling the morphology evolution of the herein called Type- 2 pockmark by the formation/decomposition of gas hydrates. According to Sultan et al. (2014), rapid gas hydrate growth and slow hydrate dissolution are the main mechanisms leading to the development of Type-2 pockmarks and sub-seafloor architecture. Davy et al. (2010) suggest that the size of these Type-2 pockmarks linked to the presence of gas hydrates depends on slumping and translation along the overpressured BGHS that may have contributed to their morphology. Imbert and Ho (2012) propose a conical shape failure 
generated by gas hydrate formation to explain $1 \mathrm{~km}$-diameter paleo-funnel-shaped collapse features. Although the above studies open an essential way forward in our understanding of Type-2 pockmarks, they are lacking a precise description of the geo-mechanical process triggering the sedimentary deformation due to gas hydrate formation. The main aim of the present work is to identify the key mechanical process connecting gas hydrate formation to the initiation of sub-surface sediment fracturing and deformation.

The Eastern Niger Submarine Delta (ENSD; Figure 2), situated in deep-water "Niger Delta", deserves attention because it is an active area for the oil industry and, apart from pockmarks expressed at the seafloor (e.g. George and Cauquil, 2007), many seep-related seafloor features have been recently described as a consequence of gas hydrates decomposition (e.g. Sultan et al., 2014). The ENSD is therefore an important source of hazards for deep-water infrastructures and a suitable site to study the potential link between gas hydrate and sub-surface deformation features. In this work we focus on a specific area, where very high resolution bathymetry data reveal a Type-2 pockmark (Figure 2). Based on the combined analysis of very high resolution (VHR) seismic lines, sedimentological and geotechnical data, we investigate the pockmark to define a conceptual model describing the mechanical process at the origin of the sedimentary deformation observed above gas hydrates. Finally, we use numerical modelling to check assumptions and working hypotheses about the link between pockmarks shape and the gas hydrate formation and distribution.

\section{Background}

\subsection{The Eastern Niger Submarine Delta}

The study area concerns a sub-surface deformation feature named "pockmark" situated on the northern flank of the shale-cored anticline EB named and described in Riboulot et al. (2012) and it lies at $750 \mathrm{~m}$ water depth. It is located in the ENSD, on the continental margin off the Niger Delta, on the middle continental slope dominated by folding and faulting in response to rapid sedimentation rates and shale remobilization (eg. Morley and Guerin, 1996). Indeed, major structural faults have been identified beneath the pockmark and described in Ruffine et al. (2013) and Sultan et al. (2011). These vertical 
discontinuities constitute gas migration pathway from the deep structure to the upper sedimentary layers. The late Quaternary interval of the ENSD consists of a stack of mud-dominated sedimentary sequences separated by coarse-grained planktonic foraminifera and other sand-size particles marked by high amplitude reflectors in seismic data (D10 to D40; Figure 2 3; Riboulot et al., 2012). After burial, the layers with grain size coarser than encasing sediment becomes a potential gas reservoir (Riboulot et al., 2013).

\subsection{Two types of pockmarks in the ENSD}

In the ENSD, recent studies have detailed examples of pockmarks related to dewatering, presence of fault systems, buried mass transport complexes, fluid escape from petroleum reservoirs and gas hydrate dissolution/dissociation (e.g. Sultan et al., 2010; Riboulot et al., 2013). Type-1 Pockmarks have a regular circular or near circular shape often associated to a symmetric depression (Figure 1.a). They vary in diameter from about 10 to $900 \mathrm{~m}$ and the depth of the depression below the regional trend of the seafloor ranges from about 0.1 to $50 \mathrm{~m}$. When pockmarks are observed in vertical sections (seismic profile), depressions are typically eroded first and then filled with sediment as their activity ceases. They are often associated with an underlying chimney or acoustic "pipes" (e.g. Hustoft et al., 2007; Løseth et al., 2011). Chimneys are characterized by an interruption of seismic reflectors due to the gas charge (wipeout zone) (Hovland, 1984), an inflection of seismic reflectors corresponding to a velocity pull down effect (e.g. Hustoft et al., 2010), an upward bending reflections corresponding to a velocity pull up artefact due to enhanced concentration of gas hydrate or authigenic carbonate cement link to the presence of carbonates or gas hydrates (e.g. Hustoft et al., 2007), and a deformation of sedimentary layers within fluid-escape conduit.

Type-2 pockmarks show irregular seafloor morphology with distorted shape and are rimmed by a ring depression or circular moat (Figure 1.b). This peripheral zone is characterized by a high dip value reaching up to $15^{\circ}$. Type- 2 pockmarks vary in diameter from around 50 to $800 \mathrm{~m}$, and the depth of the depression at the seafloor is about $10 \mathrm{~m}$. In seismic sections, Type- 2 pockmarks are characterized by the presence of a very high-amplitude chaotic seismic facies (HACF) below the seafloor deformation (Riboulot et al., 2011), corresponding to the location of massive gas hydrates (Sultan et al., 2010; 2014). 
Unlike Type-1 pockmarks, Type-2 pockmarks are not associated with vertical chimney.

\subsection{Gas hydrate pockmarks: stages and mechanical processes}

Type-2 pockmarks, linked to decomposition of gas hydrates bearing underlying sedimentary layers, may have different stages of maturation. Previous studies by Sultan et al. $(2010,2014)$ detailed the chronological stages that the seafloor morphology may follow in response to the formation/destabilization of gas hydrates. The first stage corresponds to an uplift of the upper sedimentary layers due to gas hydrate formation but hydrates are formed before any type of deformations affects the seafloor (Sultan et al., 2014). This stage is followed by a collapse with a ring depression at the seafloor generated by the dissolution of solid hydrates at the border of the gas hydrate occurrence zone (Stage 2). The final stage of the Type-2 pockmark formation corresponds to the disappearance of the solid hydrate and the cease of fluid activity leading to the formation of an irregular crater. Many studies were undertaken to explain and characterize the controlling factor at the origin of the dissolution/dissociation of the gas hydrates but to our best knowledge none of them have attempted to explain the geo-mechanical mechanism controlling the associated irregular seafloor and sub-seafloor deformations.

\subsection{The pockmark of interest}

The large pockmark, about $300 \mathrm{~m}$ in diameter and $6 \mathrm{~m}$ deep, is located on the northern flank of the shalecored fold EB in about $745 \mathrm{~m}$ water depth (Figure 2). It is situated at the north of the zone studied by Sultan et al. (2011) showing a pockmark field composed by Type-1 and Type-2 pockmarks. It has a roughly square shape with steep terrains in its central part. The bathymetric section of the pockmark shows an irregular shape with a relief in its central part (Section B-B' in Figure 2). The maximal depth of the depression at the seafloor may reach $6 \mathrm{~m}$ and the flanks of the pockmark are steeper than Type-1 pockmarks with a slope that can reach $25^{\circ}$ locally (Figure 2). In the central part of the pockmark, we observe the mark of a major normal fault oriented SW-NE, documented in Ruffine et al. (2013). This Type-2 pockmark presented here correspond to the stage 2 of the model of Sultan et al. (2014). 


\section{Tools and Methods}

Geophysical, geotechnical and geological data used in this work were acquired during a joint research and development project (called ERIG3D) between Ifremer and Total in 2008.

\subsection{Geophysical data}

The primary source of data is VHR 2D seismic data acquired using the deep towed device SYSIF and a deep-sea sub-bottom profiler. The SYSIF, a recently developed deep-towed seismic acquisition system (Marsset et al., 2010; Ker et al., 2010), provides images of the first $100 \mathrm{~ms}$ twtt below seafloor with a resolution of about $0.5 \mathrm{~m}$ thanks to acoustic transducers working in the 580-2200 Hz frequency range, and a $15 \mathrm{~m}$ long dual channel streamer (example of seismic profile is presented in Figure 3). More details about SYSIF are given by Ker et al. (2010) and Marsset et al. (2010). The deep-sea sub-bottom profiler, developed by IXSEA and IFREMER (Le Gall et al., 2008), consists of a single light transducer working in the $1.8 \mathrm{kHz}-6.2 \mathrm{kHz}$ frequency band and a three hydrophones array as a receiver. This system was mounted on an autonomous underwater vehicle (AUV) to acquire seismic lines at constant altitude (80 $\mathrm{m})$. The vertical resolution is close to $20 \mathrm{~cm}$.

Multibeam data from an AUV site survey, provided by Total, were used to characterize the bathymetry and the seafloor morphology at a detailed scale with a resolution of 3 meters.

\subsection{Sediment core data}

Calypso piston cores CS22 (Figure 4) and CS30 (Ruffine et al., 2013) were collected in the central part of the irregular morphology at water depths of 746 and $740 \mathrm{~m}$, respectively (Appendix 14). Sediment core analyses included physical property measurements (bulk density, P-wave velocities, magnetic susceptibility with a Geotek Multi Sensor Core Logger - MSCL), sedimentological description and continuous major element analysis (eg. Ca, Sr, Ti) with an Avaatech XRF core scanner (Richter et al., 2006). Based on the evaluation of coring parameters during operations using the "CINEMA" software (Bourillet et al., 2007), sediment perturbation during coring is considered as negligible. The core data acquired in this study are correlated to seismic reflection profiles. 


\subsection{In situ geotechnical measurements}

In situ geotechnical measurements (Cone Penetration Tests with pore pressure measurements, CPTu and Vp) were carried out with the Penfeld penetrometer. This device developed by Ifremer allows to perform piezocone tests as deep as 30 meters below the seafloor. Piezocones characteristics are presented in Appendix 14.

\subsection{Numerical calculation}

Finite element simulations were carried out using a commercial finite element software called PLAXIS 8.2 (Brinkgreve et al., 2006). The finite element package has been developed specifically for the analysis of deformation and stability in geotechnical engineering projects under drained and undrained conditions and it allows the use of different linear and non-linear constitutive models for fine and coarse sediments. The information required for defining the sediment mechanical and physical properties can be obtained from a combination of laboratory geotechnical tests and in situ measurements. In the present work, the Mohr-Coulomb linear-elastic perfectly plastic model is used (for more details see Brinkgreve et al., 2006).

\section{Gas hydrate, sand occurrence and internal architecture of the gas-hydrate-pockmark}

\subsection{Evidence from geophysical data}

Very high-resolution (VHR) seismic sections crossing the studied pockmark show the detail architecture of the sedimentary layers (Figure 3 and Appendix 11). The seismic facies is continuous and sub-parallel (Mitchum et al., 1977). Several high-amplitude reflections (D40, D30, D20 and D10) correspond to coarse grain size layers identified in Riboulot et al. (2012) and can play the role of gas storage zone (Riboulot et al., 2013). Seismic analysis of sedimentary layers outside the studied pockmark reveals local interruptions and seismic reflection deflections under Type-1 pockmarks marking surely presence of fluid chimneys (Figure 3). The area underlying the studied pockmark is characterized by the presence of a high-amplitude chaotic seismic facies (HACF) at about 15 meters below the seafloor (mbsf) and the absence of an associated vertical chimney (Figure 3). The HACF has a "V" shaped profile along a 
SW-NE cross-section and has approximately the same horizontal extent as the seafloor pockmark. However, when crossed in the NW-SE direction (Appendix 11), the HACF is divided into 2 areas either side of the major fault projected here from the interpretation made in Ruffine et al. (2013). Seismic profiles acquired with AUV show the top of the HACF while Sysif data were useful to interpret the base of the package. With the AUV system, the seismic response is affected by presence of gas and a strong gas acoustic shadow which prevents observation of the base of HACF. Above the HACF and under the central part of the pockmarks, sediments with discernible internal structure are deformed upward (Figure

3). Contrary to what was observed in Type-1 pockmarks where sediments inside the pockmark are eroded, Type-2 pockmarks show a keystone of host sediments with sedimentary series inside the pockmark matching those outside. As in the case of Type-1 pockmark chimney, the peripheral zone of the pockmark loses its internal structure.

To summarize the observations, Figure 5 provides a comprehensive sketch of the pockmark morphology and associated sub-seafloor HACF zone which in this view is divided into two blocks by the major fault. The area affected by fluid activities is localized under the sub-surface sedimentary deformation marked by the pockmark.

\subsection{Evidence from sedimentary sampling}

The HR seismic profiles acquired through the studied pockmark show an uplift of the sedimentary layers (D40 and D30) above HACF (Figure 3). Calypso core CS22, with a length of $9.27 \mathrm{~m}$ have sampled D40 (Figure 4) and, intersects this regional reflector at around $1.5 \mathrm{mbsf}$. Core and geophysical data shows that the D40 high amplitude can be correlated to a level of carbonate concretions characterized by a

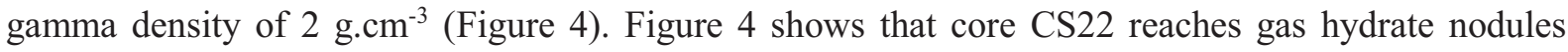
associated with cracks and carbonates at 6 mbsf. The bulk density values presented in Figure 4 are perturbed by the presence of cracks and fluidized sediments generated by gas hydrate decomposition. In addition, core CS30 (described in Ruffine et al., 2013), with a length of $6.71 \mathrm{~m}$, confirms the above description of core CS22. 


\subsection{Evidence from in situ measurements}

In the present work, only CPTu and Vp measurements acquired along seismic profiles are commented and included in Figure 3 (Appendix 11). The details of CPTu and Vp measurements presented in Appendix 12 and Appendix 13 show the cone resistance versus depth obtained respectively from three sites located surrounding the studied pockmark (CPT16S01, CPT18S01 and Vp17S08) and six sites located within the studied pockmark (CPT16S02, CPT16S05, CPT16S06, CPT14S06, Vp17S05 and Vp17S06).

For this study, we focus on the detection of gas hydrates and permeable coarse sedimentary layers which have a major role in fluid migration. In situ piezocone measurements, carried out by Sultan et al. (2007), show that the distinction between gas hydrates and carbonate concretions can be done thanks to the excess pore pressure generated during the rod penetration. Gas-hydrate-bearing sediments seem to be characterized by a specific type of piezocone data showing a strong increase of the cone resistance accompanied by a strong increase of the pore pressure, while silty/sandy layers and carbonates are characterized by high tip resistance, high friction and low pore pressure.

Far from the pockmark, at the CPT18S01 reference site, cone resistance and pore pressure increase linearly with depth showing the presence of homogeneous sediment. The sharp increase of the cone resistance (peaks) at $7 \mathrm{mbsf}$ and $21 \mathrm{mbsf}$ combined with a decrease in pore pressure indicates the presence of silty/sandy layers (Appendix A and B). The correlation with seismic interpretation reveals that those two silty/sandy layers correspond respectively to the high amplitude reflections D40 and D30 (Appendix 12) confirming that the lithology of these high amplitude reflectors is composed of coarser grain size layer than the encasing sediment, as described by Riboulot et al. (2012).

By contrast to observations made on CPT18S01, the CPT16S01 site is too close to the pockmark in morphologically disturbed zone and cannot be a considered as a reference site although it is positioned outside the pockmark (Appendix A and B). The CPT16S01 cone resistance and pore pressure increase linearly with depth showing the presence of homogeneous sediment over the first $8 \mathrm{mbsf}$. Several sandy and/or carbonate layers are present between $8 \mathrm{mbsf}$ and $15 \mathrm{mbsf}$ with the possible presence of free gas. The rod refusal at around $15 \mathrm{~m}$ is probably due to presence of sand and/or carbonates. 
Within the concerned pockmark, four CPTu are characterized by early refusal at depths ranging from 10 to $14 \mathrm{~m}$ (CPT16S02, CPT16S05, CPT16S06 and CPT14S06) (Figure 3 and Appendix A and C). Calibration of the seismic line indicates that rod refusal occurs at the transition between two seismic facies on the HACF zone indicating that this last facies is characterized by a very high cone resistance exceeding $10 \mathrm{MPa}$ (Figure 3). The cone resistance peaks for the four sites CPT16S02, CPT16S05, CPT16S06 and CPT14S06, presented in Appendix 13, reveal the presence of gas hydrates at several depths within the pockmark. Many levels of high cone resistance associated to a low excess pore pressure were considered as the geotechnical signature of silty/sandy layers. On the other hand, the same geotechnical response in terms of high cone resistance and low excess pore pressure can be the signature of piezocone penetration through carbonate concretions layers (Sultan et al., 2007).

Three sites were investigated with the sonic cone. In situ $\mathrm{P}$ wave velocity measured at the reference site (Vp17S08) shows a small linear increase with depth indicating the presence of homogeneous sediment (Appendix A and B). Two drops in values of $\mathrm{Vp}$ at about $8 \mathrm{mbsf}$ and $21 \mathrm{mbsf}$ associated with an increase of the attenuation indicate the presence of permeable layers. This result is in agreement with observations from CPT18S01 and the correlation with the seismic profile AUV04Pr17 showing the presence of two permeable layers corresponding to D40 and D30 reflectors. It is important to note that the slight increase of the $\mathrm{Vp}$ value at site $\mathrm{Vp} 17 \mathrm{~S} 08$ is associated with a loss of the signal at the same depth. Vp measurements at sites Vp17S05 and Vp17S06 within the pockmark are both characterized by an early refusal at $14 \mathrm{mbsf}$. The two sites show the presence of a silty/sandy layer at $3 \mathrm{mbsf}$ that matches well with CPTu data. In summary, the D40 permeable layer is at about 7 mbsf outside the pockmark and at about 4 mbsf within the pockmark. This permeable layer is uplifted within the pockmark.

\section{Gas hydrates, fluid flow and seafloor deformation: mechanical process}

\subsection{Hydrate pockmark morphology and internal architecture}

Evidence about the internal architecture of the gas-hydrate-pockmark was obtained through a combination of geophysical, sedimentological, and geotechnical data. Figure 5 is a block diagram showing the pockmark morphology, its internal architecture and the fault described by Ruffine at al. 
(2013) considered as a gas migration pathway feeding the V-shaped HACF zone. The previous studies of Sultan et al. (2014) and Wei et al. (2015) about gas hydrate pockmarks in Niger Delta show the HACF zone correspond to the presence of massive gas hydrates associated with the presence of free gas alveoli isolated within massive gas hydrate zone. The coexistence between free gas and gas hydrates could be responsible of the presence of the high reflectors within the V-shaped area. Observations about the Vshaped zone made from geophysical data, sediment samples and in situ geotechnical measurements are consistent with the interpretation of the HACF as the seismic signature of the presence of massive gas hydrates in the study area. The V-shaped zone, corresponding to a 3D conical body, is rooted in a coarsegrain layer that can play a role in gas lateral migration and may constitutes a transient gas migration zone. Above the V-shaped zone, several nodules of gas hydrates disturbed the shallow sedimentary layers (Figure 4.b), that have been uplifted by the formation of massive gas hydrates. Type-2 pockmarks show a keystone of host sediments, pushed up by gas hydrates, with sedimentary series inside the pockmark matching those outside.

\subsection{The conical body of gas hydrates}

The conical body of the massive gas hydrates has many similarities with the morphology of magmatic intrusions showing an average dip of $20^{\circ}$ (Hansen and Cartwright, 2006), with the conical sand intrusions and their discordant limbs having an average dip of $26^{\circ}$ (Shoulders et al., 2007) and with the interpreted fossil hydrate pockmarks described in Imbert and Ho (2012) with their conical failure planes having an average angle of $10^{\circ}$ to $25^{\circ}$.

The V-shaped anomaly described here in the seismic sections develops above a major fault that was described in Ruffine et al. (2013) as a gas migration pathway feeding the gas hydrate zone. The intermediate gas reservoir or the "parent bed" in the sense of Vigorito and Hurst (2010), is confined in underlying sedimentary units at around $600 \mathrm{mbsf}$ (Ruffine et al., 2013). Comparable to models proposed by Cartwright et al. (2008), Mathieu et al. (2008), Vigorito and Hurst (2010) and Mourgues et al. (2012), where vertical feeder dykes connect parent beds to "V" shaped features that can be a conical sandstone intrusion or a magmatic saucer-shaped intrusion, the major normal fault in the present study area connects the intermediate gas reservoir to the massive gas hydrate zone. Although several geometrical 
similarities between the gas hydrate pockmarks and sandstone intrusion exist, the mechanical process seems to be slightly different.

\subsection{Mechanical process generating the conical fracture}

The growth of a gas hydrate core in sedimentary layers seems analogue to common process describing magmatic intrusions observed by Hansen et al. (2006) and gas dome evolution model proposed by Barry et al. (2012). The accumulation and growth of material within soft cohesive sediments generate a forced fold or a seafloor dome above the material. Several models in literature attempts to characterize mechanically the origin of this V-shape: according to Hansen et al., 2006, the accumulation of gas hydrates generates peripheral fractures (Stage 2 of the schematic kinematic model - Figure 14 in Hansen et al., 2006); Imbert and Ho (2012) suggest that fossil conical collapse features are the result of failure of the shallow sediment triggered by the volume increase related to hydrate formation; experiments developed by Mourgues et al. (2012) support that pore pressure field generated around an overpressured parent body favours the formation of inclined sheet-like fractures and is at the origin of conical fracture formations; Gay et al. (2012) compare the conical fracturation geometries observed in sandbox modeling with the seismically observed geometries of the Giant Gjallar Vent and show the vertical conduit transforms into distributed fluid flow with a V-shaped structure. In the present study, our working hypothesis is that the dome above the hydrate plug is directly linked to the mechanical fracturation occurring after gas hydrate formation at the base of the structure (Figure 3). To check this hypothesis, we numerically reproduced the laboratory experiments carried out by Mourgues et al. (2012) by considering that the formation of a hydrate plug induces an upward movement of overlying sediments. We believe that the pore pressure applied by Mourgues et al. (2012) causes an upward movement of the overlying sediments instead of a pore fluid build-up in the overlying porous materials. Indeed, the gas entry pressure in these experiments is expected to be higher than the lithostatic pressure due to the weight of the used materials. We used the Plaxis geotechnical software using the geometry and mechanical properties of the material used in Mourgues et al. (2012). Mohr-Coulomb was used as a constitutive model describing the material behaviour. The pressure applied at the base of the experiment developed by Mourgues et al. (2012) is simulated numerically as an upward vertical movement of a piston. Figure 
6 shows the numerical calculation results in terms of shear strain compared to the experimental results of Mourgues et al. (2012) and illustrates the perfect agreement between these two results, confirming that the mechanical process behind the conical fracture is provoked by a piston-like movement rather than a build-up of pore pressure. In the following, the upward movement generated by gas hydrate accumulation and growth will be considered as the main mechanical process behind the V-shaped HACF area.

\section{Numerical modelling of the initiation of the gas-hydrate-pockmark}

The main aim of the following numerical calculations is to identify the mechanical process and the major parameters controlling gas hydrates accumulation and hydrate propagation in $\mathrm{V}$-shaped fractures.

\subsection{Numerical calculations: initial conditions, geometry model and imposed}

\section{displacement}

Because the pockmark is ring-shaped, numerical simulations have been carried-out in an axisymmetric geometry (Figure 7.a). The sediment above the gas hydrate formation zone was modelled as one homogeneous shale layer because the preliminary calculations have shown that including the two thin layers of sand (D30 and D40) in the simulation has no impact on the numerical results. The standard fixities (zero displacement) are used for the boundary conditions as for most geotechnical applications. The initial model before deformation corresponds to the horizontal homogeneous sedimentary layer without any deformation or preexisting discontinuities as it is shown in Figure 7.b $(\mathrm{t}=0)$. The gas hydrate growth is assumed to correspond to an upward motion of a stiff plate (see Figure 7.b) with variable geometry. The imposed differential displacements rise from zero at the border of the plate to reach a maximum variable value at the center (Figure 7.b).

The finite element mesh involved 15-node triangular elements with refined mesh used in critical regions above the hydrate plug (Figure 8.a). The Mohr-Coulomb properties of the material and other parameters used for the numerical simulation are in Appendix E.

In the following, a parametric study has been carried out by varying the radius of the stiff plate (a), the 
thickness of the sediment overlying the hydrate plug (h), the internal friction angle of the shale and the velocity of the stiff plate motion. All calculations were conducted under drained and undrained conditions. An example of the numerical calculation results is shown in Figure 8 in terms of deformed mesh (Figure 8.a), total displacement (Figure 8.b), shear strains (Figure 8.c), plastic points (Figure 8.d) and excess pore pressure for undrained conditions (Figure 8.e). A summary of the parametric calculation results is presented in Figure 9.

\subsection{Numerical calculations: parametric study}

We conducted 16 numerical calculations to examine the impact of the lateral size (a) and the vertical size (h) of the hydrate zone on the fracturation (Fig. 7.a). We have represented the result of the calculations in four graph detailed in the Figure 9. The ratio of the plate size (a) to the overburden thickness (h). For the 16 numerical calculations, a/h was comprised between 0.25 and 2 . For example, the scenario where $\mathrm{a} / \mathrm{h}=0.25$ is where the radius of the hydrate plug would be a quarter ooof the overburden. For all of the calculation, we observe on the shear strain (Figure 8.c) the formation of fractures with a $\mathrm{V}$-shaped structure. The critical value of $\mathrm{a} / \mathrm{h}$ corresponding to the maximum angle of the $\mathrm{V}$-shape was also calculated showing that for all of the calculations where $\mathrm{a} / \mathrm{h}$ was greater than two, two fractures have formed reaching an angle of $45^{\circ}$.

The numerical analyses are discussed in the following by considering (i) the effect of "a" on the fracture planes geometry and size and (ii) the effect of the gas hydrates growth on the seafloor deformations and the excess pore pressure evolution with time.

\section{Size of the gas hydrate zone (a)}

The size and shape of fractured areas depend on the gas hydrate lateral extension zone. Fracture angle obtained from the 16 calculations showed that it increases with the increase of $a / h$ when the maximum imposed displacement "w" was taken equal to $1 \mathrm{~m}$ (Figure 9.a). The dip is not always easy to calculate because the facture geometry tends to curve under some imposed initial and geometrical conditions. Hence, a mean dip is taken from measurements on the first centimeters of fractures above the stiff plate simulating the hydrate plug. The angle reaches a maximal value of $42-43^{\circ}$ when "a" is greater than " $\mathrm{h}$ " 
or "a" is greater than $5^{*} \mathrm{w}$. For "a" less than $0.25^{*} \mathrm{~h}$ or "a" equal " $\mathrm{w}$ " ( $\mathrm{a}=\mathrm{w}$ means the radius of the hydrate plug is as large as its height), the failure surface is not conical and it becomes impossible to simulate the development of a V-shaped fracture.

From the geophysical data acquired from the present pockmark, it was observed that the angle of the Vshape is equal to $20^{\circ}$. From Figure 9.a and for a fracture angle of $20^{\circ}$, the a/h value is found equal to 0.42 and the a/w value equal to 2.1 . For the study area, the thickness of the sediment above the initial hydrate plug was evaluated to $42 \mathrm{~m}$ (Figure 3), which allows us to derive a radius of the hydrate zone "a" of $18 \mathrm{~m}$ and a maximum upward displacement "w" of $8.6 \mathrm{~m}$. From "a" and "w" it is possible to calculate an initial volume of the gas hydrate plug of ca. $3000 \mathrm{~m}^{3}$ at the origin of the observed $20^{\circ}$ fracture planes.

\section{Size of the seafloor bulge over the gas hydrate core}

The vertical bulge at the seafloor, named vertical deflection " $\mathrm{w}$ ", is dependent of the displacement induced by gas hydrate growth. The 16 simulations show a logarithmic relation between $\mathrm{w}^{1} / \mathrm{w}$ and $\mathrm{a} / \mathrm{h}$ which reaches a maximal value of 0.5 when $\mathrm{a} \geq \mathrm{h}$ (Figure 9.b). Therefore, for "a" greater than or equal to " $\mathrm{h}$ ", the bulge at the seafloor is less than half of the maximal thickness " $\mathrm{h}$ " of the gas hydrate plug. The impact of the deformation onto the seafloor is smaller for $\mathrm{a}<\mathrm{h}$. For the studied pockmark and the considered a/h, w'/w is expected to be equal to 0.33 (Figure $9 . \mathrm{b}$ ). For "w" equal to $8.6 \mathrm{~m}$, "w" is expected to be equal to $2.8 \mathrm{~m}$. This value of "w" matches well with the $3.2 \mathrm{~m}$ obtained from geophysical data (Figure 3).

The inverse logarithmic curve of a'/a (signification of "a" in Figure 7.b) as a function of a/h reaches out a minimal value of 1.8 to 1.6 when $\mathrm{a} \geq \mathrm{h}$ (Figure 9.c). Figure 9.c shows that a'/a decreases with the increase of $\mathrm{a} / \mathrm{h}$ ratio. For $\mathrm{a}<\mathrm{h}$, the spatial extent of the bulge at the seafloor is at least 2 times larger than the bulge at the gas hydrate core. For the studied pockmark, a'/a is equal to 2.3 inducing an "a"" value equal to $41 \mathrm{~m}$.

\section{Effect of the hydrate growth rate on excess pore pressure under undrained conditions}

The undrained behavior in the clay layers causes the development of excess pore pressure during upward 
displacement generated by hydrate growth. The excess pore pressure varies with time and decreases to 0 at the end of the dissipation phase (Figure 9.d). For the used Plaxis software, negative pore pressure indicates excess pore pressure while positive pore pressure corresponds to suction.

Simulation results carried out under undrained conditions show after the applied vertical displacement "a" a negative pore pressure above the stiff plate and positive pore pressure at the seafloor level revealing an extensional state due to the bulge induced by the piston movement (see for instance Figure 8-e). We can suspect a fracturation of this zone below the seafloor similar to the formation of extrados faults due to tectonic folding. Excess pore pressure seems to diminish exponentially with time and after 6 months, almost all the excess pore pressure and suction are dissipated. At a geological scale 6 months can be considered as negligible and therefore the initial pockmark formation can be considered to take place under drained conditions where the pore pressure is considered equal to the hydrostatic one.

\section{Summary}

The unknown characteristics of the gas hydrate dome before fracturing were derived from numerical simulations. The initial state of the pockmarks before fracturation corresponds to the formation of a gas hydrate core $36 \mathrm{~m}$ in diameter and about $9 \mathrm{~m}$ high located $40 \mathrm{~m}$ below the seafloor. This generated an uplift of the overlying sedimentary column expressed at the seafloor by a bulge $80 \mathrm{~m}$ in diameter with a maximum height of $2.6 \mathrm{~m}$.

\section{Evolution of the Type-2 pockmarks}

In the following we proposed a simplistic kinematic model to represent the growth of the gas-hydrate pockmark. The model is illustrated with reference to two stages determined from geophysical observation and modelling experiments. The two stages are far apart in time.

Phase 1 (Figure 10.a) - The origin of the pockmark formation is linked to the presence of faults crossing gas hydrate-bearing sedimentary units, similar to what has been proposed elsewhere by several independent studies (e.g., Papatheodorou et al. 1993). Once the ascending free gas following vertical discontinuities crosses the local base of gas hydrate stability zone, gas hydrates are formed within the deep cohesive clay in vertical fractured zones (Sultan et al., 2014). Indeed, in case free methane-rich gas 
migrates upward into shallow sediment, where fluid pressure and crystallization force exceed the effective overburden stress, it spreads out in the pore space and reacts with water, forming gas hydrate (Torres et al., 2004). When the upwards pressure exerted by the free gas exceeds the sum of the mechanical strength of the overlying gas hydrates and the minimum principal stress, gas breaks through the overlying fracture-filling hydrates (Simonetti et al., 2013).

The excess pore pressure due to free gas accumulation within the gas hydrate stability zone can therefore provoke a growth of hydrates into lateral direction in softer sediment. This process seems similar to what was previously described for conical intrusions where a small laccolith of sand is formed at the top of a vertical feeder dyke (Cartwright et al., 2008), although the size is smaller. For the present case study, at around 40 mbsf, the base of the massive gas hydrate area overlies a coarse-grain sedimentary layer more permeable than the surrounding cohesive clay materials (D10 in Figure 3). The gas, migrating laterally in this sandy layer, forms the first stage of the gas hydrate pockmark, in the sense of Sultan et al. (2010), which generates an initial bulge at the seafloor. The amount and rate of lateral gas propagation and gas hydrate formation depends mainly on the mechanical properties of the surrounding sediments. The dome forms by progressive growth of gas hydrates that deforms the overburden. Conical fractures begin to propagate upward. In our case, the hydrate plug was initiated at about 40 mbsf. The hydrate body had an initial diameter of $36 \mathrm{~m}$ and a thickness of $8 \mathrm{~m}$ when fracturing was initiated (Figure 9). Seafloor deformation induced by the hydrate growth is materialized by a bulge $80 \mathrm{~m}$ in diameter and 3 $\mathrm{m}$ high. Following this deformation, fracturing at an angle of $20^{\circ}$ developed above the gas hydrate plug similar to what was already observed in magmatic intrusions (angles ranging from 10 to $30^{\circ}$; Hansen and Cartwright, 2006), or in sand intrusions (average angles $26^{\circ} \pm 2^{\circ}$; Shoulders et al., 2007), or in funnels-shaped collapse features (average angle of 10 to $25^{\circ}$, Imbert and Ho, 2012). Moreover, the parametric studies showed that according to the initial diameter of hydrates, fracturing angles can reach a maximum of $44^{\circ}$ when $\mathrm{a}>\mathrm{h}$.

Phase 2 (Figure 10.b) - Fractures attain seafloor. The migration of gas through these discontinuities is responsible for the formation of a V-shaped massive gas hydrate core and feeds sedimentary layers D40 and D30, where gas hydrate nodules were recovered. Hydrates are stable under high pressure, low temperature, moderate salinity, and saturated gas conditions (e.g., Sloan and Koh, 2008). Gas hydrate 
dissolution may occur when hydrate comes in contact with an aqueous phase undersaturated in methane (e.g., Lapham et al., 2010). Pore water concentration profiles of dissolved methane and sulfate measured in the uppermost $6 \mathrm{~m}$ of CS30 (Figure 5 in Ruffine et al., 2013), show a low methane concentration above the hydrate nodules in the central part of the studied pockmark confirming the dissolution process at the top of the gas hydrate occurrence zone. Dissolution of gas hydrates may therefore be responsible of deformations and collapse within overcoming sedimentary layers.

\section{Conclusions}

While pockmarks and gas hydrates have been recognized and described all around the oceans, we extend the known range of the architecture and the formation processes of these features in four ways:

(1) We described the morphology of the Type-2 pockmarks directly associated to the presence and decomposition of gas hydrates with a detailed description of the sub-seafloor sedimentary layers and gas hydrates distributions;

(2) We provided a conceptual model for Type-2 pockmark formation by identifying the mechanism behind the initial stage of pockmark development with the formation of the conical fracture;

(3) We defined thanks to numerical calculations and parametric studies a relationship between geometric parameters characterizing Type-2 pockmarks;

(4) We determined thanks to the parametric studies, the geometry and volume of the gas hydrate accumulation zone underlying the present study pockmark.

The present work is an important step in understanding the mechanism of gas-hydrate-pockmark initiation. It opens the way for a quantitative analysis of the formation/evolution and dynamic of gashydrate pockmarks. Such quantitative analysis is an essential step in the assessment of geotechnical hazards related to the presence of such active structures but also to evaluate the danger related to degassing of greenhouse gases into the oceans and ultimately into the atmosphere.

This work is also part of a scientific understanding of the dynamics of sedimentary deformation related to migration of gas, sand, magma, mud, etc., and provides a new point of view in the knowledge of seafloor deformations related to the formation of gas hydrates. 


\section{Acknowledgements}

This work has been developed and funded by Ifremer and Total, through a post-doctoral fellowship to the first author. The work is based on interpretation of data from ERIG3D project. The support by officers and crew during the ERIG3D cruise on board R/V "Pourquoi Pas ?" (2008) is greatly appreciated, as is the dedication of the Genavir and Ifremer technical staff during the cruise. We thank sincerely the two anonymous reviewers and the editor P. Shearer for their stimulating comments and suggestions.

\section{References}

Barry, M.A., Boudreau, B.P., Johnson, B.D., 2012. Gas domes in soft cohesive sediments. Geology 40, 379-382.

Bourillet, J.-F., Damy, G., Dussud, L., Sultan, N., Woerther, P., Migeon, S., Behaviour of a piston corer from accelerometers and new insights on quality of the recovery.

Brinkgreve, R.B.J., Broere, W., Waterman, D., 2007. Plaxis 2D manual. Delft: Delft University of Technology.

Cartwright, J., James, D., Huuse, M., Vetel, W., Hurst, A., 2008. The geometry and emplacement of conical sandstone intrusions. Journal of Structural Geology 30, 854-867.

Cathles, L.M., Su, Z., Chen, D., 2010. The physics of gas chimney and pockmark formation, with implications for assessment of seafloor hazards and gas sequestration. Marine and Petroleum Geology 27, 82-91.

Chand, S., Thorsnes, T., Rise, L., Brunstad, H., Stoddart, D., Bøe, R., Lågstad, P., Svolsbru, T., 2012. Multiple episodes of fluid flow in the SW Barents Sea (Loppa High) evidenced by gas flares, pockmarks and gas hydrate accumulation. Earth and Planetary Science Letters 331, 305-314.

Davy, B., Pecher, I., Wood, R., Carter, L., Gohl, K., 2010. Gas escape features off New Zealand: Evidence of massive release of methane from hydrates. Geophysical Research Letters 37.

Eichhubl, P., Greene, H.G., Naehr, T., Maher, N., 2000. Structural control of fluid flow: offshore fluid seepage in the Santa Barbara Basin, California. Journal of Geochemical Exploration 69, 545-549.

Forwick, M., Baeten, N.J., Vorren, T.O., 2009. Pockmarks in Spitsbergen fjords. Norwegian Journal of Geology 89, 65-77.

Gay, A., Mourgues, R., Berndt, C., Bureau, D., Planke, S., Laurent, D., Gautier, S., Lauer, C., Loggia, D., 2012. Anatomy of a fluid pipe in the Norway Basin: Initiation, propagation and 3D shape. Marine Geology 332, 75-88.

George, R.A., Cauquil, E., 2007. AUV ultrahigh-resolution 3D seismic technique for detailed subsurface investigations. Offshore Technology Conference. Houston, TX, USA. OTC 18784.

Hansen, D.M., Cartwright, J., 2006a. Saucer-shaped sill with lobate morphology revealed by 3D seismic data: implications for resolving a shallow-level sill emplacement mechanism. Journal of the Geological Society 163, 509-523.

Hansen, D.M., Cartwright, J., 2006b. The three-dimensional geometry and growth of forced folds above saucer-shaped igneous sills. Journal of Structural Geology 28, 1520-1535.

Hovland, M., Judd, A.G., King, L.H., 1984. Characteristic features of pockmarks on the North Sea Floor 
and Scotian Shelf. Sedimentology 31, 471-480.

Hovland, M., Svensen, H., Forsberg, C.F., Johansen, H., Fichler, C., Fosså, J.H., Jonsson, R., Rueslåtten, H., 2005. Complex pockmarks with carbonate-ridges off mid-Norway: products of sediment degassing. Marine Geology 218, 191-206.

Hustoft, S., Bünz, S., Mienert, J., 2010. Three-dimensional seismic analysis of the morphology and spatial distribution of chimneys beneath the Nyegga pockmark field, offshore mid-Norway. Basin Research 22, 465-480.

Hustoft, S., Mienert, J., Bünz, S., Nouzé, H., 2007. High-resolution 3D-seismic data indicate focussed fluid migration pathways above polygonal fault systems of the mid-Norwegian margin. Marine Geology $245,89-106$.

Imbert, P., Ho, S., 2012. Seismic-scale funnel-shaped collapse features from the Paleocene-Eocene of the North West Shelf of Australia. Marine Geology 332, 198-221.

Judd, A., Hovland, M., 2007. Seabed fluid flow. The impact on geology, biology and the marine environment. Cambridge University, Cambridge.

Judd, A.G., Hovland, M., Dimitrov, L.I., Garcia Gil, S., Jukes, V., 2002. The geological methane budget at continental margins and its influence on climate change. Geofluids 2, 109-126.

Ker, S., Marsset, B., Garziglia, S., Le Gonidec, Y., Gibert, D., Voisset, M., Adamy, J., 2010. Highresolution seismic imaging in deep sea from a joint deep-towed/OBH reflection experiment: application to a Mass Transport Complex offshore Nigeria. Geophysical Journal International 182, 1524-1542.

King, L.H., MacLean, B., 1970. Pockmarks on the Scotian shelf. Geological Society of America Bulletin 81, 3141-3148.

Lapham, L.L., Chanton, J.P., Chapman, R., Martens, C.S., 2010. Methane under-saturated fluids in deep-sea sediments: Implications for gas hydrate stability and rates of dissolution. Earth and Planetary Science Letters 298, 275-285.

Le Gall, Y., Pacault, A., Mosca, F., Greninguey, G., Vial, M., Aissa, J.C., 2008. Ultra-deep lowfrequency sub-bottom profiler for AUV and ROV. The Journal of the Acoustical Society of America $123,3234-3234$.

Leifer, I., Judd, A.G., 2002. Oceanic methane layers: the hydrocarbon seep bubble deposition hypothesis. Terra Nova 14, 417-424.

Løseth, H., Wensaas, L., Arntsen, B., Hanken, N.-M., Basire, C., Graue, K., 2011. 1000 m long gas blow-out pipes. Marine and Petroleum Geology 28, 1047-1060.

Macelloni, L., Simonetti, A., Knapp, J.H., Knapp, C.C., Lutken, C.B., Lapham, L.L., 2012. Multiple resolution seismic imaging of a shallow hydrocarbon plumbing system, Woolsey Mound, Northern Gulf of Mexico. Marine and Petroleum Geology 38, 128-142.

Marsset, T., Marsset, B., Ker, S., Thomas, Y., Le Gall, Y., 2010. High and very high resolution deeptowed seismic system: Performance and examples from deep water Geohazard studies. Deep Sea Research Part I: Oceanographic Research Papers 57, 628-637.

Mathieu, L., Van Wyk De Vries, B., Holohan, E.P., Troll, V.R., 2008. Dykes, cups, saucers and sills: Analogue experiments on magma intrusion into brittle rocks. Earth and Planetary Science Letters 271, $1-13$.

Mitchum Jr, R.M., Vail, P.R., Sangree, J.B., 1977. Seismic stratigraphy and global changes of sea level: Part 6. Stratigraphic interpretation of seismic reflection patterns in depositional sequences: Section 2. Application of seismic reflection configuration to stratigraphic interpretation.

Morley, C.K., Guerin, G., 1996. Comparison of gravity-driven deformation styles and behavior associated with mobile shales and salt. Tectonics 15, 1154-1170.

Mourgues, R., Bureau, D., Bodet, L., Gay, A., Gressier, J.B., 2012. Formation of conical fractures in 
sedimentary basins: Experiments involving pore fluids and implications for sandstone intrusion mechanisms. Earth and Planetary Science Letters 313, 67-78.

Papatheodorou, G., Hasiotis, T., Ferentinos, G., 1993. Gas-charged sediments in the Aegean and Ionian Seas, Greece. Marine Geology 112, 171-184.

Pilcher, R., Argent, J., 2007. Mega-pockmarks and linear pockmark trains on the West African continental margin. Marine Geology 244, 15-32.

Riboulot, V., Cattaneo, A., Berné, S., Schneider, R.R., Voisset, M., Imbert, P., Grimaud, S., 2012. Geometry and chronology of late Quaternary depositional sequences in the Eastern Niger Submarine Delta. Marine Geology 319, 1-20.

Riboulot, V., Cattaneo, A., Lanfumey, V., Voisset, M., Cauquil, E., 2011. Morphological signature of fluid flow seepage in the Eastern Niger Submarine Delta (ENSD). Offshore Technology Conference, Houston, TX, USA. OTC 21744.

Riboulot, V., Cattaneo, A., Sultan, N., Garziglia, S., Ker, S., Imbert, P., Voisset, M., 2013. Sea-level change and free gas occurrence influencing a submarine landslide and pockmark formation and distribution in deepwater Nigeria. Earth and Planetary Science Letters 375, 78-91.

Richter, T.O., Van der Gaast, S., Koster, B., Vaars, A., Gieles, R., de Stigter, H.C., De Haas, H., van Weering, T.C.E., 2006. The Avaatech XRF Core Scanner: technical description and applications to NE Atlantic sediments. Geological Society, London, Special Publications 267, 39-50.

Ruffine, L., Caprais, J.-C., Bayon, G., Riboulot, V., Donval, J.-P., Etoubleau, J., Birot, D., Pignet, P., Rongemaille, E., Chazallon, B., 2013. Investigation on the geochemical dynamics of a hydrate-bearing pockmark in the Niger Delta. Marine And Petroleum Geology 43, 297-309.

Shoulders, S.J., Cartwright, J., Huuse, M., 2007. Large-scale conical sandstone intrusions and polygonal fault systems in Tranche 6, Faroe-Shetland Basin. Marine and Petroleum Geology 24, 173-188.

Simonetti, A., Knapp, J.H., Sleeper, K., Lutken, C.B., Macelloni, L., Knapp, C.C., 2013. Spatial distribution of gas hydrates from high-resolution seismic and core data, Woolsey Mound, Northern Gulf of Mexico. Marine and Petroleum Geology 44, 21-33.

Sloan, E.D., Koh, C.A., 2008. Clathrate Hydrates of Natural Gases, vol. 119. Boca Raton, Florida: Chemical Industries.

Solomon, E.A., Kastner, M., MacDonald, I.R., Leifer, I., 2009. Considerable methane fluxes to the atmosphere from hydrocarbon seeps in the Gulf of Mexico. Nature Geoscience 2, 561-565.

Sultan, N., Bohrmann, G., Ruffine, L., Pape, T., Riboulot, V., Colliat, J.L., De Prunelé, A., Dennielou, B., Garziglia, S., Himmler, T., 2014. Pockmark formation and evolution in deep water Nigeria: Rapid hydrate growth versus slow hydrate dissolution. Journal of Geophysical Research: Solid Earth 119, 2679-2694.

Sultan, N., Marsset, B., Ker, S., Marsset, T., Voisset, M., Vernant, A.-M., Bayon, G., Cauquil, E., Adamy, J., Colliat, J.L., 2010. Hydrate dissolution as a potential mechanism for pockmark formation in the Niger delta. Journal of Geophysical Research: Solid Earth (1978-2012) 115.

Sultan, N., Riboulot, V., Ker, S., Marsset, B., Geli, L., Tary, J.-B., Klingelhoefer, F., Voisset, M., Lanfumey, V., Colliat, J.-L., 2011. Dynamics of fault-fluid-hydrate system around a shale-cored anticline in deepwater Nigeria. Journal of Geophysical Research: Solid Earth (1978-2012) 116.

Sultan, N., Voisset, M., Marsset, T., Vernant, A.-M., Cauquil, E., Colliat, J.L., Curinier, V., 2007. Detection of free gas and gas hydrate based on 3D seismic data and cone penetration testing: An example from the Nigerian Continental Slope. Marine geology 240, 235-255.

Torres, M.E., Wallmann, K., Tréhu, A.M., Bohrmann, G., Borowski, W.S., Tomaru, H., 2004. Gas hydrate growth, methane transport, and chloride enrichment at the southern summit of Hydrate Ridge, Cascadia margin off Oregon. Earth and Planetary Science Letters 226, 225-241.

Vigorito, M., Hurst, A., 2010. Regional sand injectite architecture as a record of pore-pressure evolution 
and sand redistribution in the shallow crust: insights from the Panoche Giant Injection Complex, California. Journal of the Geological Society 167, 889-904.

Wei, J., Pape, T., Sultan, N., Colliat, J.L., Himmler, T., Ruffine, L., De Prunelé, A., Dennielou, B., Garziglia, S., Marsset, T., Peters, A.C., Rabiu, A., Bohrmann, G., 2015. Gas hydrate distributions in sediments of pockmarks from the Nigerian margin-Results and interpretation from shallow drilling. Marine and Petroleum Geology 59, 359-370.

\section{Figure captions}

Figure 1: a: Location maps of the area of interest presenting the seafloor morphology with the dip map derived from the bathymetry (horizontal resolution: $3 \mathrm{~m}$ ). We study a small area located at the north of the area studied in Sultan at al., 2011, b: The location of all data used in this study (HR seismic profiles, cores and geotechnical data) is projected on the seafloor dip map, c: The 3D view of the area of interest shows two types of seafloor deformations and the location of two bathymetric profiles. The bathymetric profiles AA' and BB' correspond, respectively, to a Type-1 pockmark and a Type-2 pockmark.

Figure 2: Geometrical characteristics of the two types of pockmarks described in the literature, a: Type1 pockmarks describe circular depressions associated to a gas chimney and are commonly observed on continental margins since 1970. Figure modified from Cathles et al. (2010) b: Type-2 pockmarks correspond to irregular and distorted depression associated in depth to the presence of gas hydrates.

Figure 3: 2D high resolution seismic profile (Sysif profile SY11-Pr03 - for location see Figure 2) with its stratigraphic interpretation showing the studied pockmark internal structure with the location and interpretation of in situ measurements and sedimentary cores. CPTu: Piezocone penetration testing and Vp: Velocity of the primary wave.

Figure 4: Calypso core CS22 recovered from the central part of the pockmark, a: log and mass density values versus depth, b: Pictures of recovered carbonates and gas hydrates.

Figure 5: 3D interpretative view of the pockmark reveals gas migration pathway from the major fault to the seafloor. The blue $\mathrm{V}$ shape corresponds to the presence of massive gas hydrate at the origin of the seafloor deformation/depression. Red arrows indicate possible fluid fluxes within the studied pockmark. Figure 6: Two different schemes showing V-shaped fracture. The upper scheme is the result of Mourgues et al., (2012) experiment showing the formation of the fractures initiated by air injection at the base of the experiment. The second scheme corresponds to the shear strain contours obtained with the commercial Plaxis software using the geometrical and mechanical characteristics of the Mourgues 
et al. (2012) experiment but where the gas pressure at the base of the sedimentary layers is replaced by a vertical imposed displacement. The two schemes show a perfect agreement in terms of deformation process and illustrate that the gas pressure applied in the Mourques et al. (2012) experiment had pushed up the sedimentary column instead of creating fractures by critical gas overpressures.

Figure 7: Initial and limit conditions used for the numerical calculation using the Plaxis software, a: 3D view of the studied area. At the base of the sedimentary column, a differential vertical displacement is applied through a stiff plate. b: 2D sketches corresponding respectively to the initial and final stages of the calculation. The meaning of the used geometrical parameters is also shown.

Figure 8: Example of Plaxis 2D numerical calculation considering the formation of a massive coneshaped core of gas hydrates $(\mathrm{h}=5 \mathrm{~m}, \mathrm{Wmax}=1 \mathrm{~m}$ and $\mathrm{a}=5 \mathrm{~m})$. Formation of gas hydrates is simulated by a differential upward movement of the stiff plate. Material properties and other parameters used in the numerical calculations are in appendix E. a: The deformed mesh, b: The total displacement, c: The shear strains showing fractures occurring above the stiff plate, d: The plastic points reveal the extension of the deformed layer, e: The values of excess pore pressure are negative over the stiff plate indicating a compressional zone and positive at the sub-seafloor in the extensive zone.

Figure 9: Four graphs summarizing the parametric studies obtained thanks to 16 numerical calculations. a: The curve of fracture angle versus $a / h$ and $a / w, b$ : The profile $w / w$ versus $a / h$ corresponding to the impact of the gas hydrate formation onto the seafloor uplift, c: The profile a'/a versus a/h demonstrating the impact of the gas hydrate formation onto the spatial extension of the seafloor deformation, $\mathrm{d}$ : The profile of the excess pore pressure versus time showing that all overpressures are dissipated one year after the formation of the gas hydrates.

Figure 10: Conceptual model (Idealized scenario) of development of Type-2 pockmark controlled by fluid seepages throughout a fault in the GHSZ. The scenario is composed of 2 phases $(a, b)$ detailed in the discussion.

\section{Appendix captions}

Appendix 11: Three 2D high resolution seismic profile (AUV) with stratigraphic interpretation of the seismic profile showing the studied pockmark internal structure with the location and interpretation of 
in situ measurements and sedimentary cores.

Appendix 12: Data and interpretation of corrected cone resistance qt and excess pore pressure $\Delta \mathrm{u} 2$ versus depth from three different sites located outside the pockmark.

Appendix 13: Data and interpretation of corrected cone resistance qt and excess pore pressure $\Delta \mathrm{u} 2$ versus depth from six sites located within the pockmark.

Appendix 14: Basic information about Calypso sediment cores and piezocone tests (CPTu and Vp).

Appendix 15: Summaries of physical properties of Niger delta sediment and various constants and parameters used in the numerical calculations. 


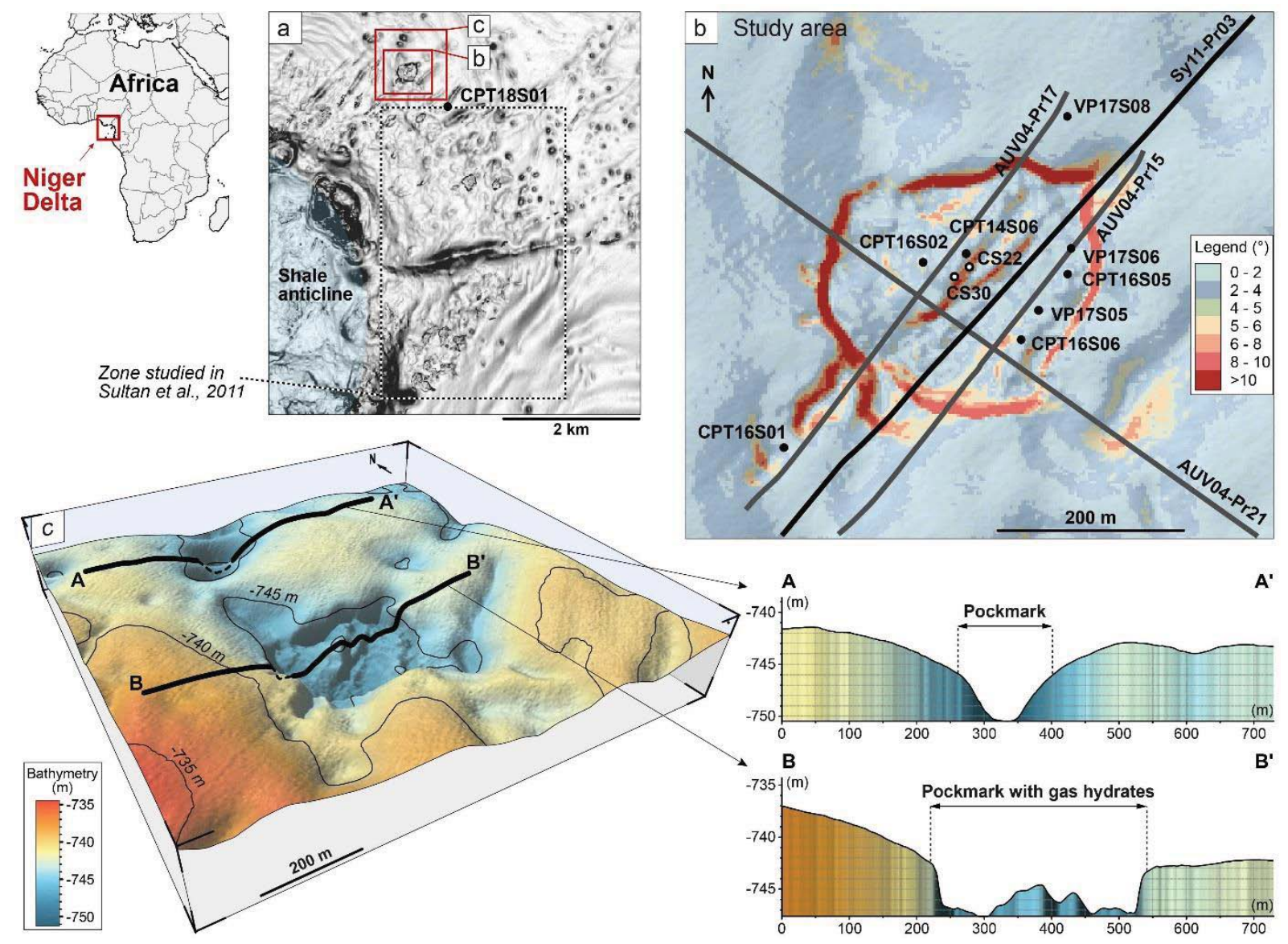

Figure 1
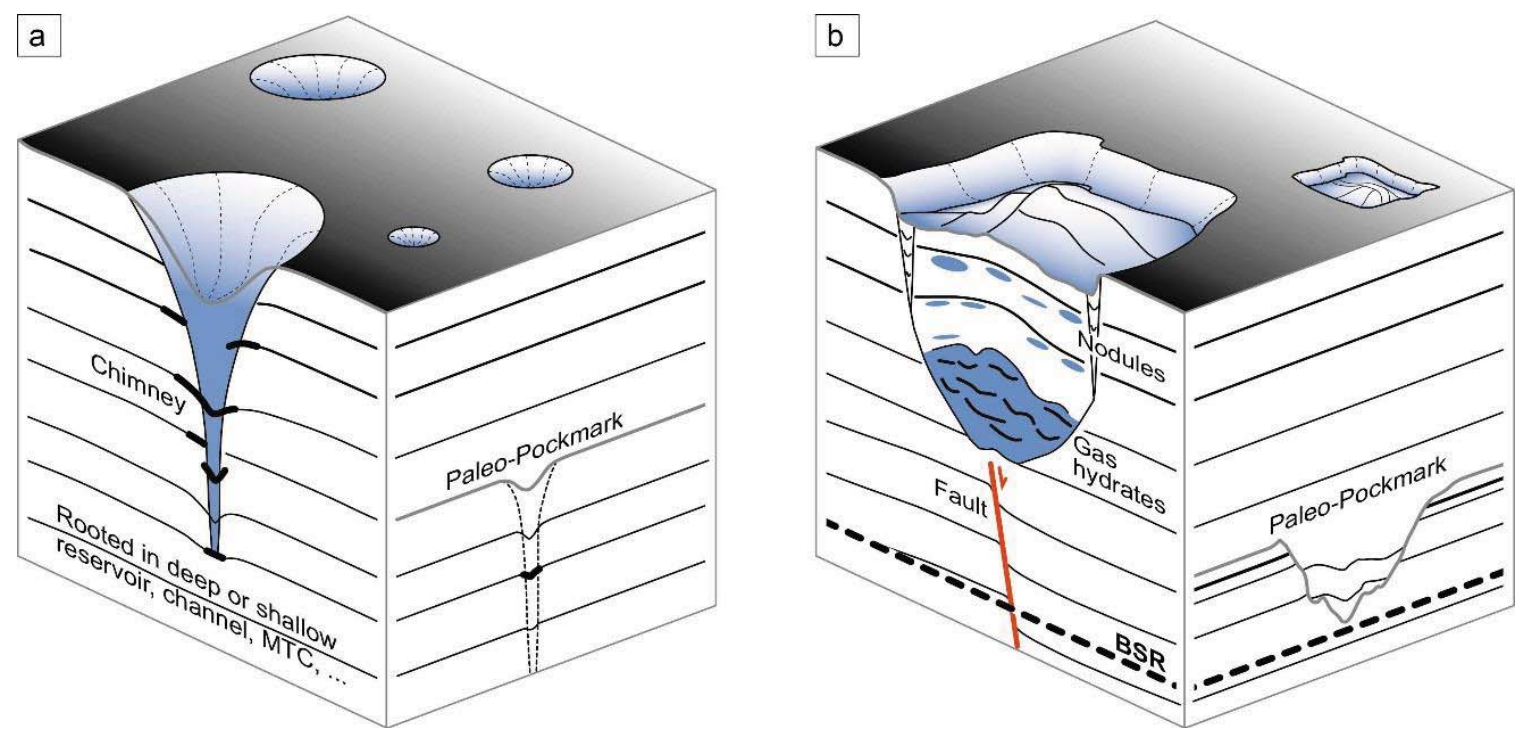

Figure 2 

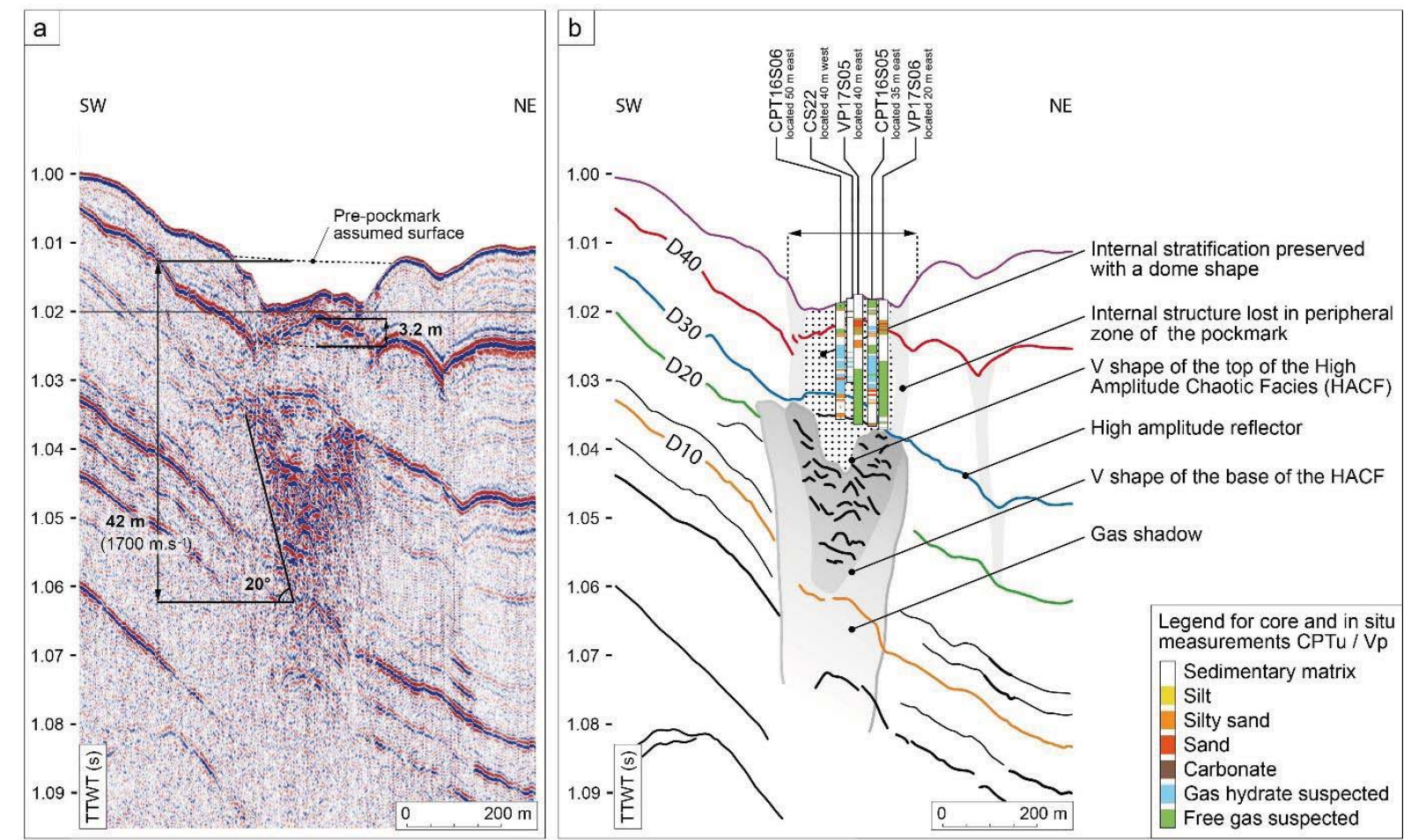

Figure 3

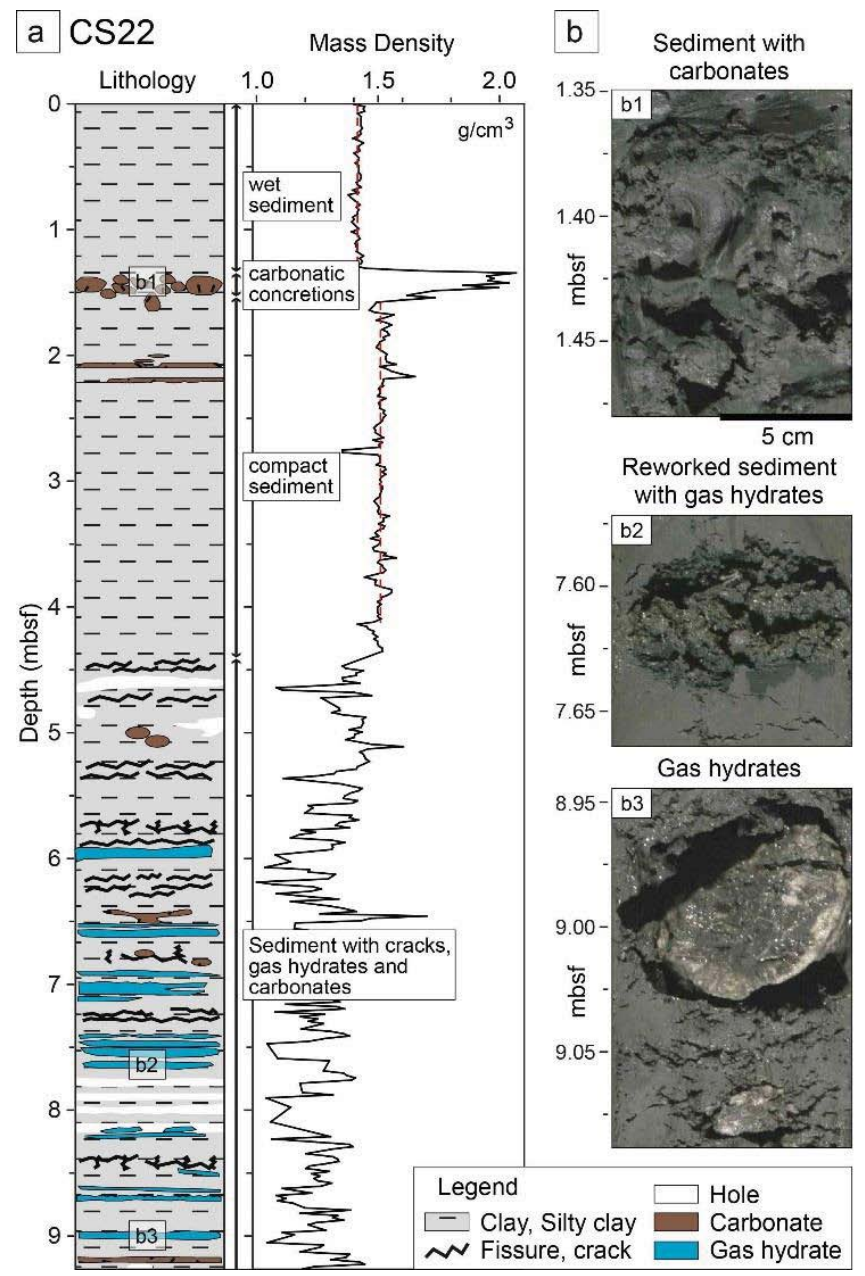

Figure 4 


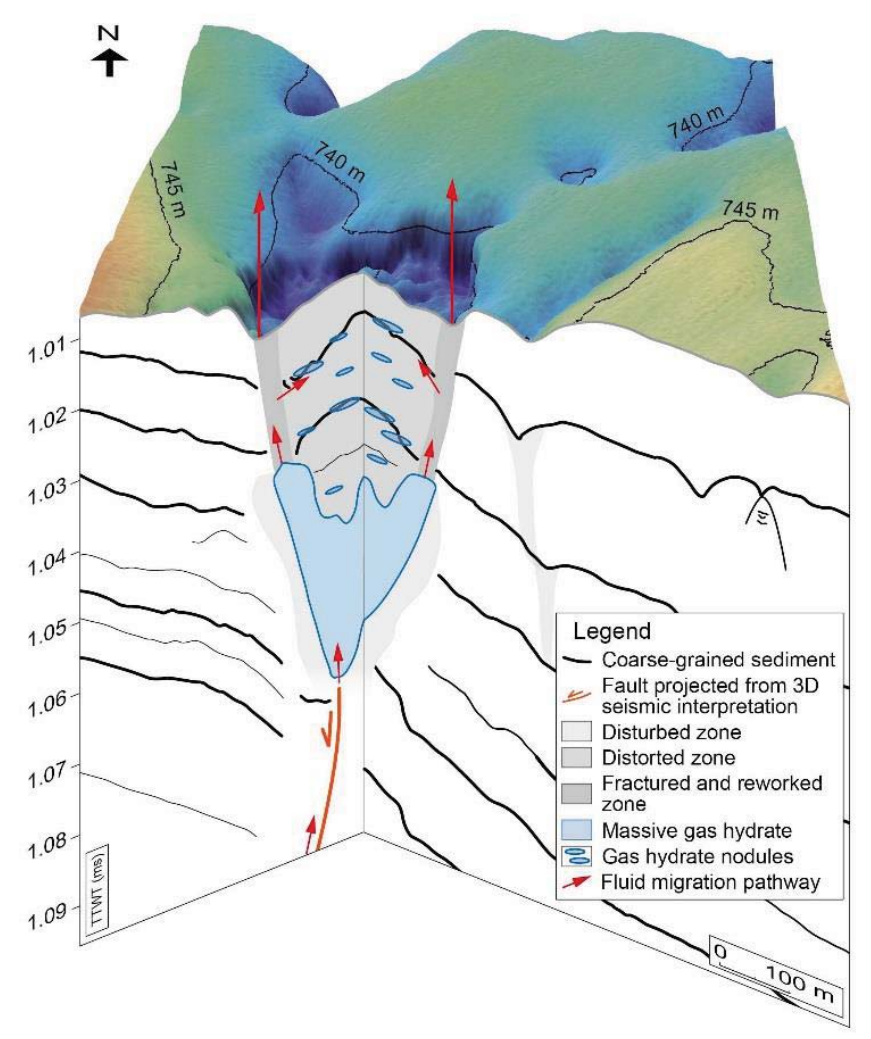

Figure 5
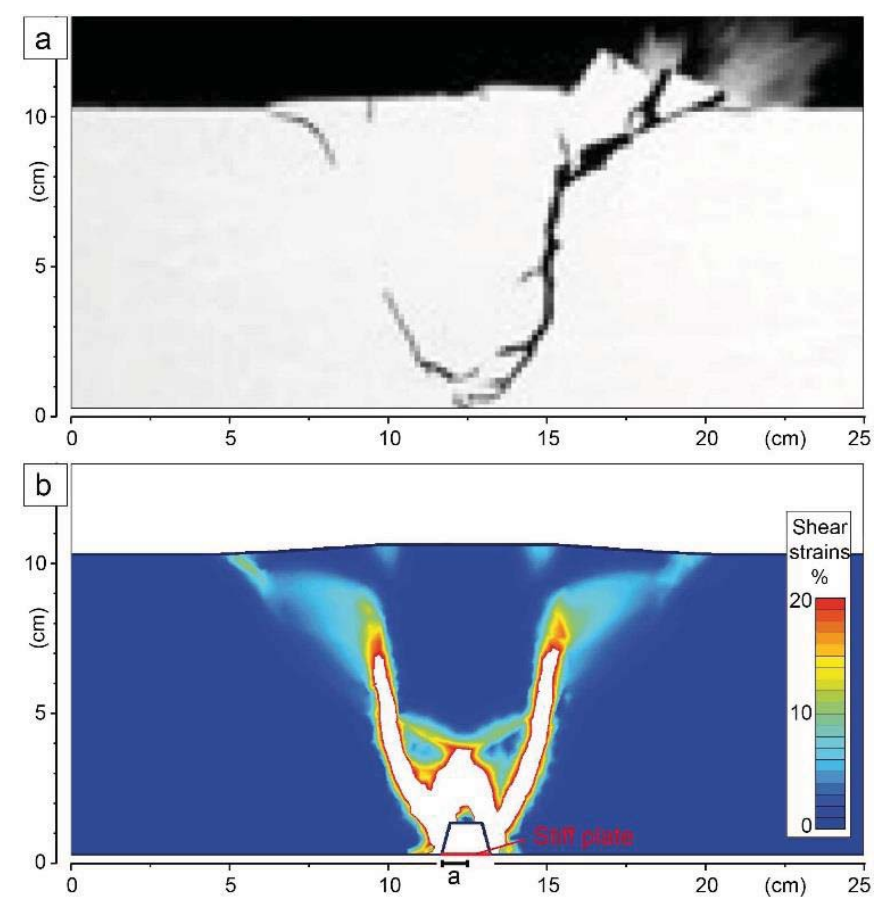

Figure 6 


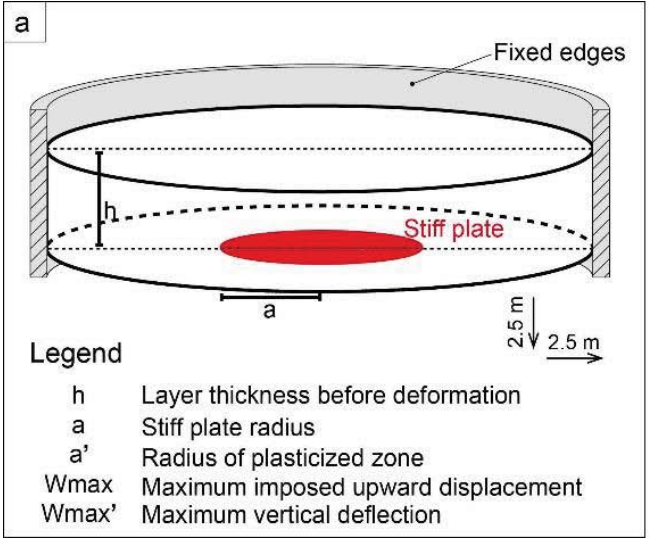

Wmax' Maximum vertical deflection

Figure 7

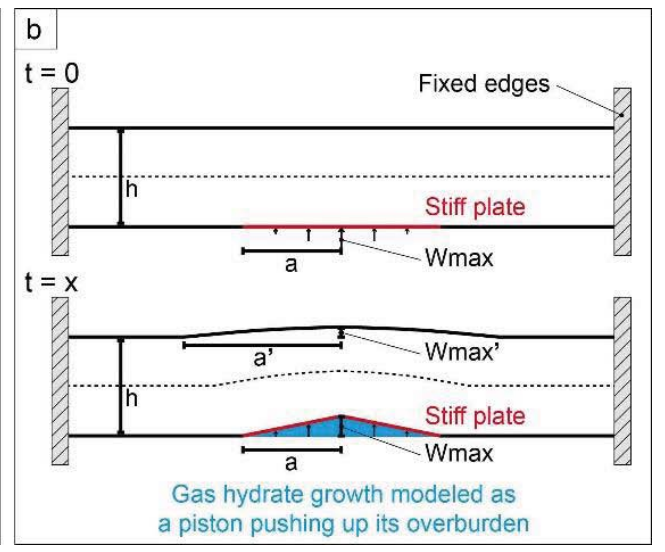

Gas hydrate growth modeled as 

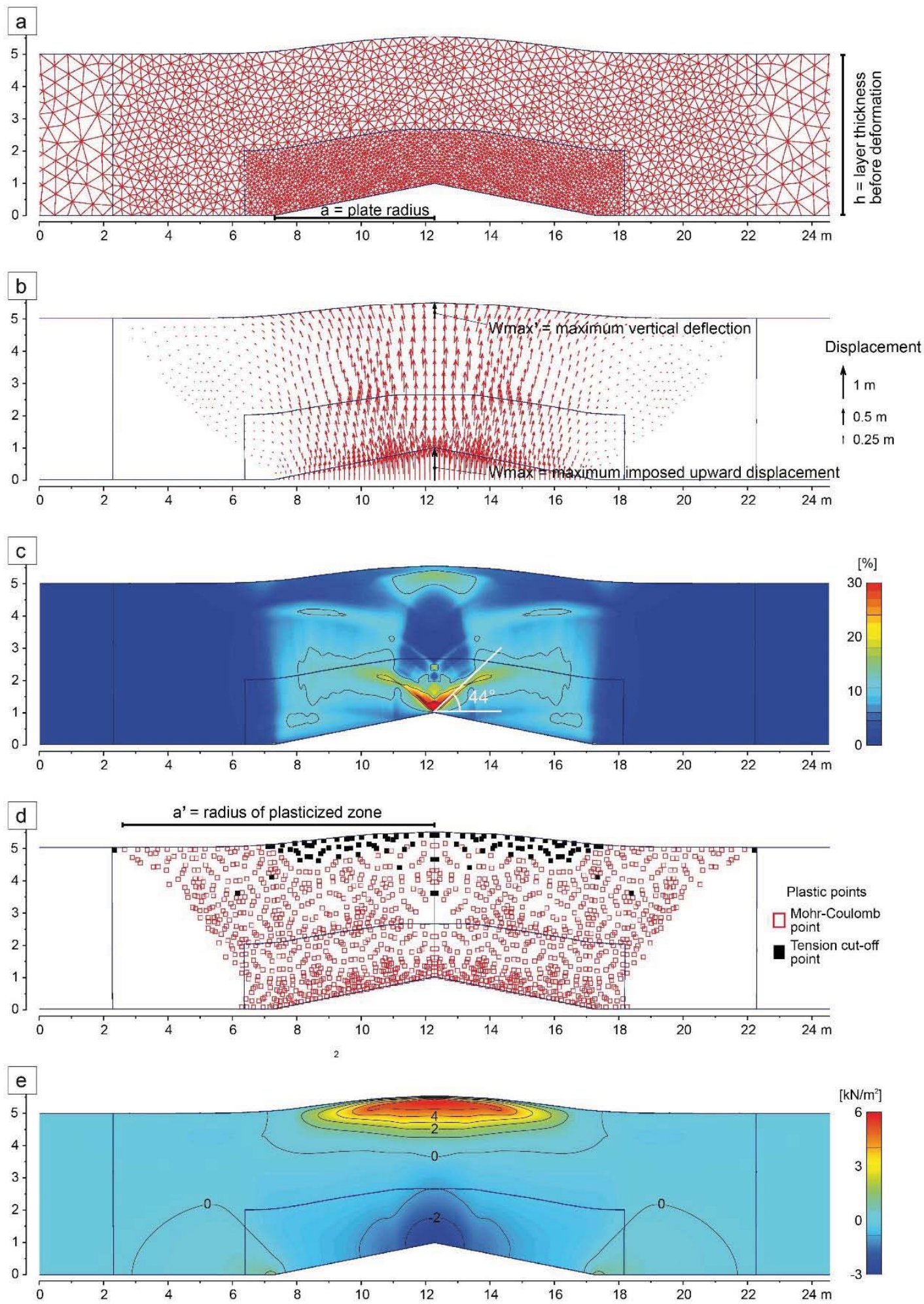

Figure 8 

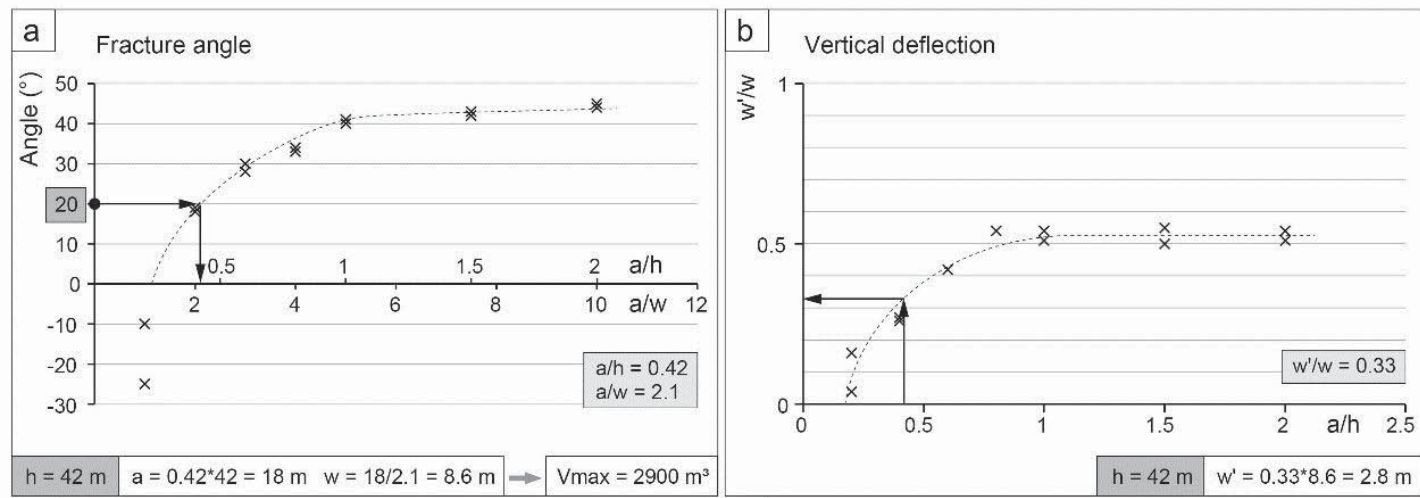

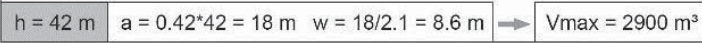
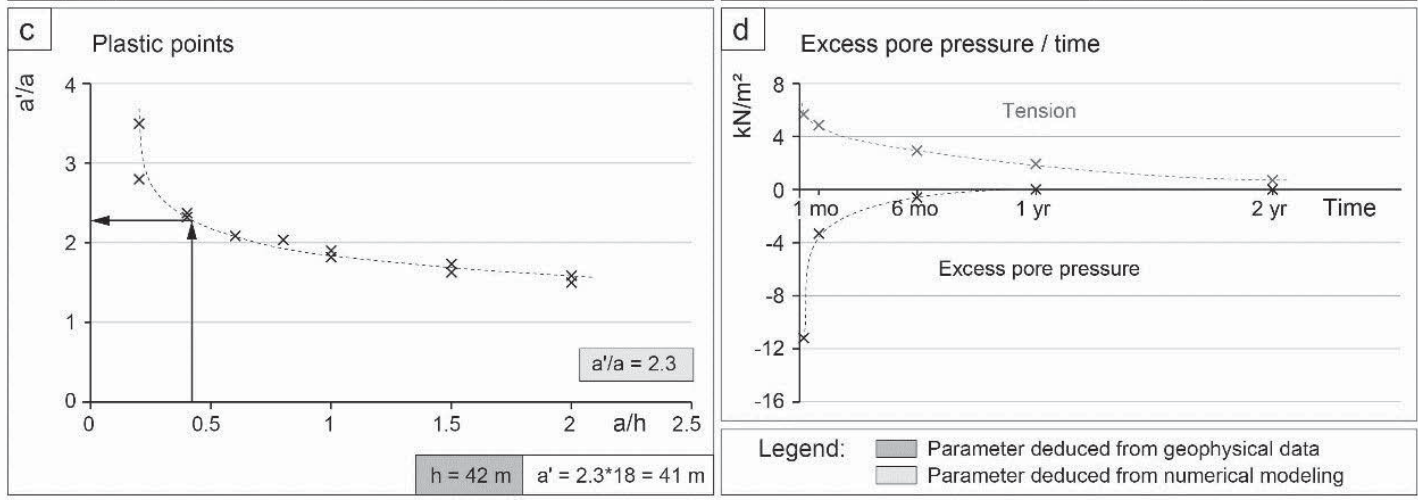

Figure 9
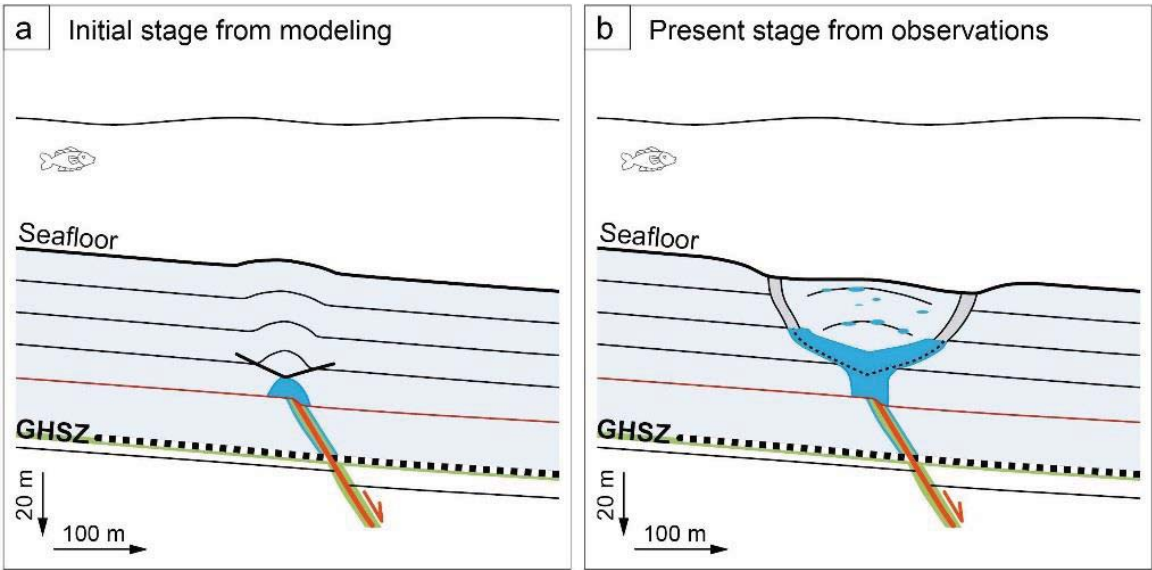 Legend
$\because=$ Gas hydrate nodules Gas hydrate
Gas hydrate stability zone (GHSZ)
Free gas
Coarse-grain layer
Fracture induced by hydrate growth
Fault = gas migration pathway

Figure 10 


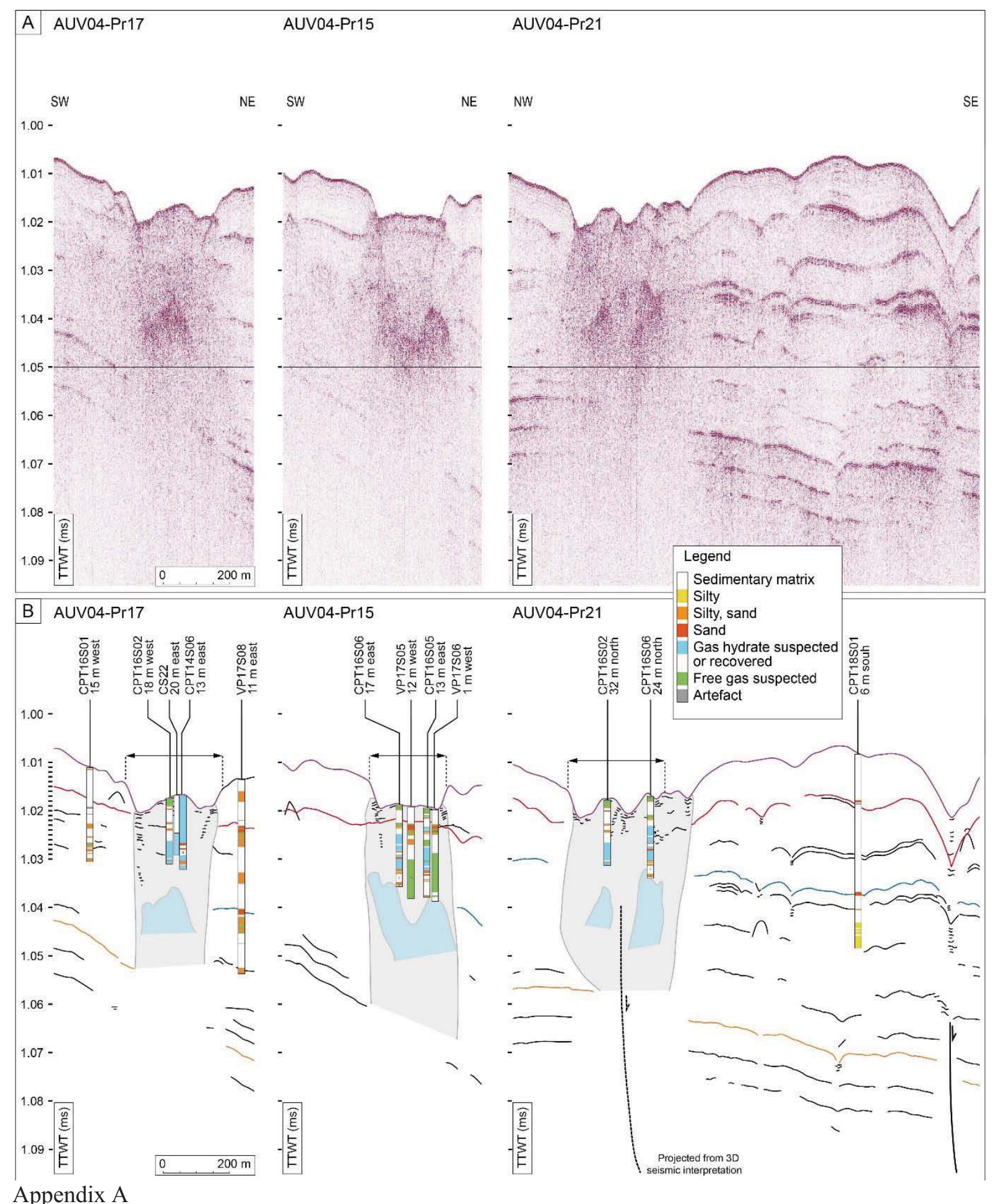




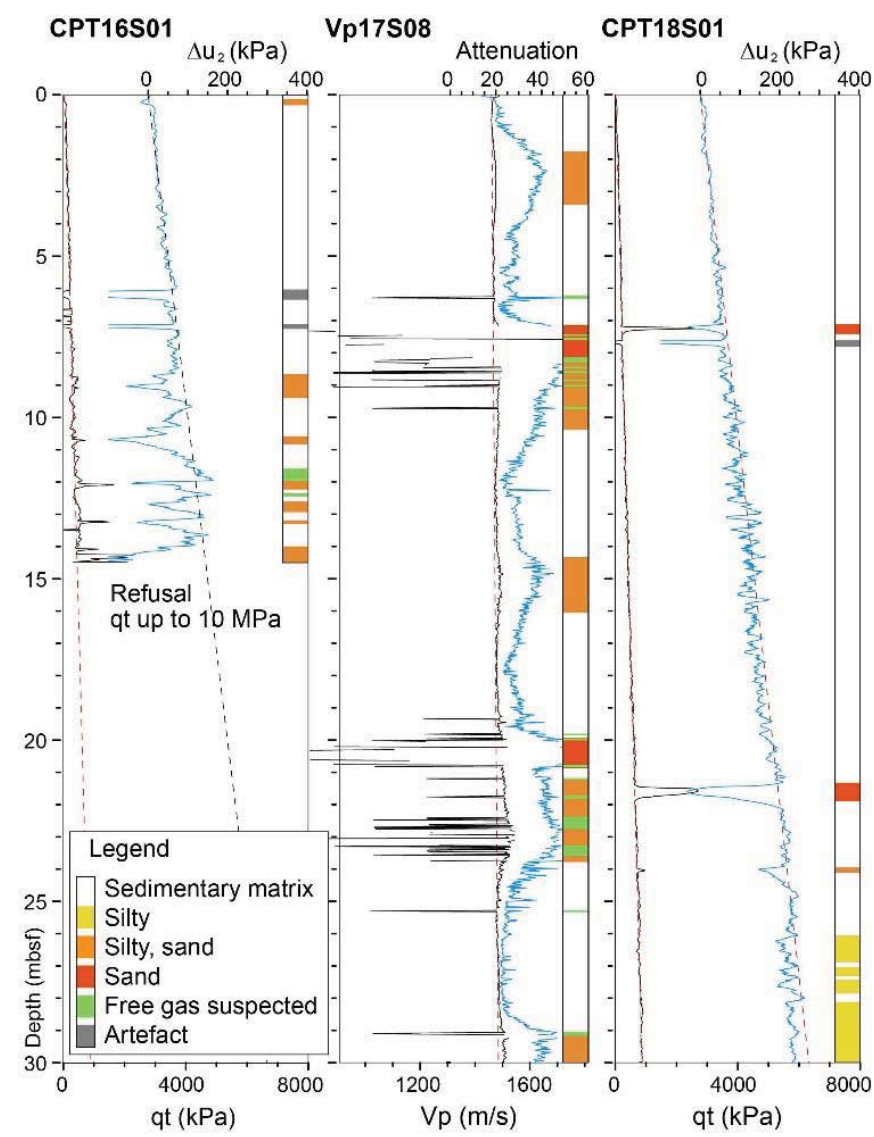

Appendix B

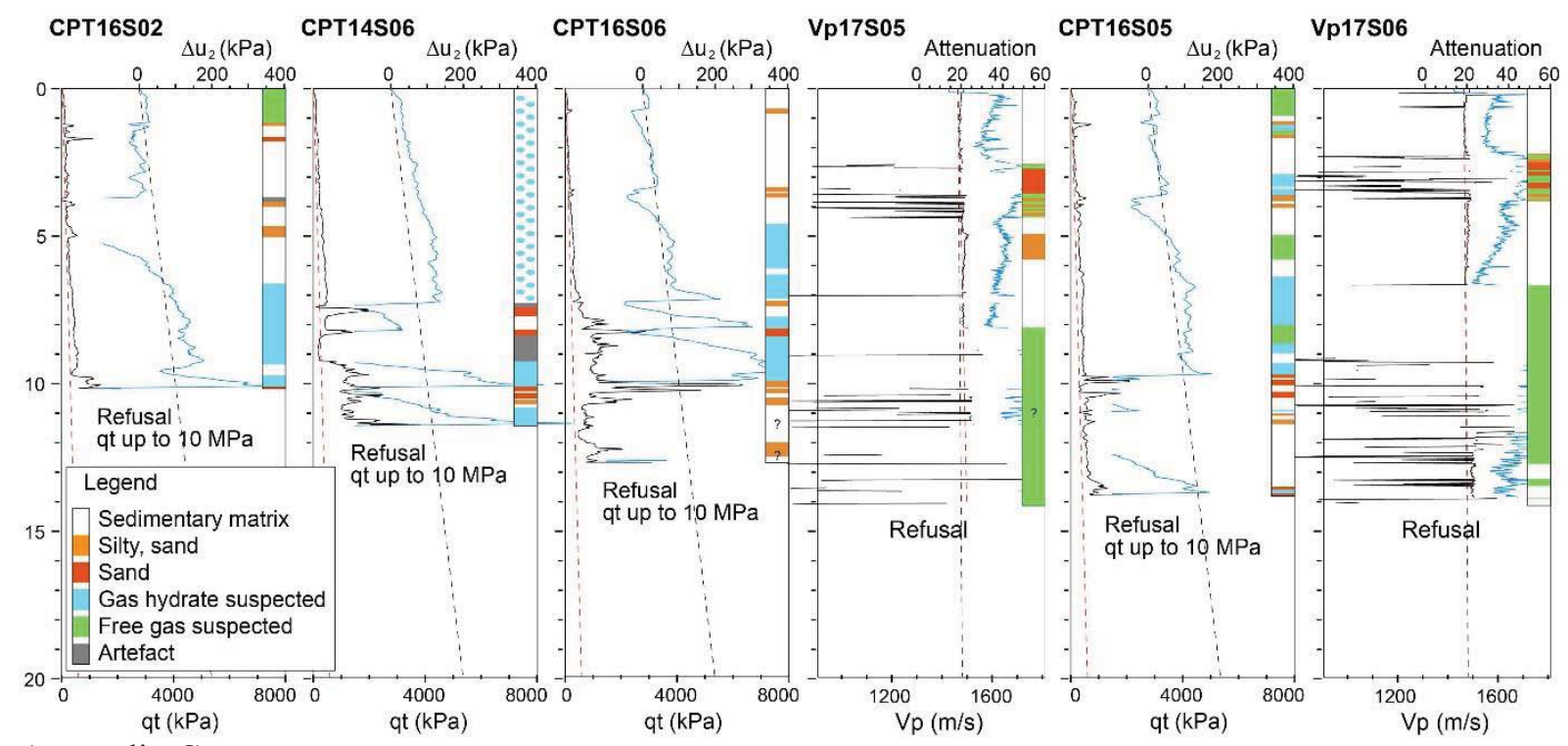

Appendix C 


\begin{tabular}{|c|c|c|c|c|c|}
\hline Name & Tool & $\begin{array}{l}\text { Length } \\
\text { (mbsf) }\end{array}$ & $\begin{array}{l}\text { Water } \\
\text { depth (m) }\end{array}$ & $\begin{array}{l}\text { Date deployed } \\
\text { (DD/MM/YY) }\end{array}$ & Observations \\
\hline CS22 & $\begin{array}{l}\text { Calypso } \\
\text { piston corer }\end{array}$ & 9.30 & 746 & $26 / 05 / 08$ & $\begin{array}{l}\text { Silty layer at about } 1.5 \mathrm{mbsf} \text { - Hydrates from } 6 \mathrm{mbsf} \\
\text { to down the core }\end{array}$ \\
\hline CS30 & $\begin{array}{l}\text { Calypso } \\
\text { piston corer }\end{array}$ & 6.71 & 740 & 04/06/08 & $\begin{array}{l}\text { Silty layers at about } 3 \mathrm{mbsf} \text { - Hydrates from } 4 \text { mbsf } \\
\text { to down the core }\end{array}$ \\
\hline CPT14S06 & CPTu & 11.46 & 748 & $21 / 05 / 08$ & Early refusal - Hydrates suspected \\
\hline CPT16S01 & CPTu & 14.51 & 740 & $25 / 05 / 08$ & Early refusal \\
\hline CPT16S02 & CPTu & 10.20 & 747 & $25 / 05 / 08$ & Early refusal - Hydrates suspected \\
\hline CPT16S05 & CPTu & 13.90 & 749 & $25 / 05 / 08$ & Early refusal - Hydrates suspected \\
\hline CPT16S06 & CPTu & 12.72 & 748 & $25 / 05 / 08$ & Early refusal - Hydrates suspected \\
\hline CPT18S01 & CPTu & 30.00 & 741 & $27 / 05 / 08$ & Cone resistance peak at 7 and 21 mbsf. \\
\hline Vp17S05 & $V p$ & 14.70 & 747 & $27 / 05 / 08$ & $\begin{array}{l}\text { Early refusal - Fall Vp and Attenuation peak at } 3 \\
\text { mbsf - Free gas suspected. }\end{array}$ \\
\hline Vp17S06 & $V p$ & 14.83 & 746 & $27 / 05 / 08$ & $\begin{array}{l}\text { Early refusal - Fall } V p \text { and Attenuation peak at } 3 \\
\text { mbsf - Free gas suspected. }\end{array}$ \\
\hline Vp17S08 & $V p$ & 30.00 & 740 & $27 / 05 / 08$ & Fall $V p$ and Attenuation peak at 8 and 21 mbsf. \\
\hline
\end{tabular}

Appendix D

\begin{tabular}{lllll} 
Parameter & Name & Clay layer & Clay layer & Unit \\
\hline Material model & Model & Mohr-Coulomb & Mohr-Coulomb & \\
Type of material behaviour & Type & Drained & Undrained & \\
Soil unit weight above phreatic level & $\gamma_{\text {unsat }}$ & 13 & 13 & $\mathrm{kN} / \mathrm{m}^{3}$ \\
Soil unit weight below phreatic level & $\gamma_{\text {sat }}$ & 14 & 14 & $\mathrm{kN} / \mathrm{m}^{3}$ \\
Permeability in horizontal direction & $k_{x}$ & $10^{-8}$ & $10^{-8}$ & $\mathrm{~m} / \mathrm{s}$ \\
Permeability in vertical direction & $k_{y}$ & $10^{-8}$ & $10^{-8}$ & $\mathrm{~m} / \mathrm{s}$ \\
Young's modulus & $E_{r e f}$ & 2000 & 2000 & $\mathrm{kN} / \mathrm{m}^{2}$ \\
Poisson's ratio & $v$ & 0.3 & 0.3 & \\
Cohesion & $c_{r e f}$ & 2 & - & $\mathrm{kN} / \mathrm{m}^{2}$ \\
Undrained shear strength & $s_{u}$ & - & $2+2 Z^{*}$ & $\mathrm{kN} / \mathrm{m}^{2}$ \\
Friction angle & $\varphi$ & 25 & 25 & $\mathrm{degree}$ \\
Dilatancy angle & $\boldsymbol{\Psi}$ & 0 & 0 & $\mathrm{degree}$
\end{tabular}

${ }^{*} S_{u}=c_{\text {ref }}+c_{\text {increment }} \boldsymbol{Z}$ with $c_{\text {increment }}=2 \mathrm{kN} / \mathrm{m}^{2}$ and $\boldsymbol{Z}=$ depth below the seafloor in meter.

Appendix E 